\title{
Computed tomography and magnetic resonance imaging of lesions at masticator space
}

\author{
Ahmed Abdel Khalek Abdel Razek
}

Received: 11 December 2013/ Accepted: 16 January 2014/Published online: 6 February 2014

(C) Japan Radiological Society 2014

\begin{abstract}
We aim to review the normal anatomy and imaging appearance of masticator space lesions. Because the masticator space is not amenable to direct examination, cross-sectional imaging with computed tomography and magnetic resonance imaging play an important role in diagnosis and characterization of lesions occurring there. Masticator space lesions can be classified on the basis of their origin into the following categories: inflammatory lesions, benign tumors, malignant tumors, vascular lesions, and developmental lesions. A diverse spectrum of malignant tumors and benign lesions are seen extending from the adjacent spaces. In addition, one should also be familiar with pseudolesions as well as post-treatment changes in the masticator space that can be mistaken for pathologic conditions.
\end{abstract}

Keywords Masticator - Infection - Benign - Malignant · MR imaging $\cdot$ CT scan

\section{Introduction}

The masticator space may be affected by inflammatory, malignant, benign, or vascular lesions arising in the masticator space proper or via extension from adjacent regions. Patients with masticator space lesions usually present with trismus, facial swelling, and pain [1]. Patients may not

Presented as educational exhibit at assembly and annual meeting of the Radiological Society of North America (RSNA) held November 27-December 2, 2011 in Chicago, IL.

A. A. K. Abdel Razek $(\bowtie)$

Department of Diagnostic Radiology, Mansoura Faculty of

Medicine, Elgomheryia Street, Mansoura 35512, Egypt

e-mail: arazek@mans.edu.eg open the mouth, and the physical examination is rather limited [2, 3]. Therefore, imaging techniques are crucial in order to provide an accurate diagnosis of lesions involving the masticator space. The clinician needs to know the nature of the lesion in the masticator space and its localization and extension into the adjacent spaces. These findings are essential for deciding therapeutic modalities as well as for appropriate planning of surgery or radiation therapy [3-5]. Table 1 shows the lesions of the masticator space.

We aim to review the normal anatomy and imaging appearance of masticator space lesions and pseudolesions.

\section{Anatomy}

The masticator space is defined by the superficial layer of the deep cervical fascia as it splits at the inferior margin of the mandible and continues superiorly. The medial division covers the medial pterygoid muscle and attaches to the skull base, whereas the lateral portion of fascia covers the masseter muscle and passes laterally to the zygomatic arch as it extends to the temporalis muscle (Fig. 1). Anteriorly, the fascia attaches in the body of the mandible at the level of the oblique line; posteriorly, the fascia connects to the posterior aspect of the ramus of the mandible [1-4].

The masticator space contains the four muscles of mastication (masseter, temporalis, medial and lateral pterygoids) [2]. This space also contains the ramus and the posterior body of the mandible, the mandibular division of the trigeminal nerve (V3) [2], and the inferior alveolar vein and artery and branches of the internal maxillary artery [3-6] (Fig. 1).

The temporal fossa, or space, is the superior extent of the masticator space superior to the zygomatic arch. Radiologists may refer to this area as the suprazygomatic 
Table 1 Classification of masticator space lesions

\begin{tabular}{|c|c|}
\hline Type & Lesions \\
\hline Inflammatory lesions & $\begin{array}{l}\text { Bacterial infection* } \\
\text { Atypical infection } \\
\text { Parasitic infection } \\
\text { Granulomatosis with polyangiitis }\end{array}$ \\
\hline Benign tumors & $\begin{array}{l}\text { Schwannoma and neurofibroma* } \\
\text { Hemangioma* } \\
\text { Lipoma } \\
\text { Fibromatosis } \\
\text { Fibrosing inflammatory pseudotumor }\end{array}$ \\
\hline Malignant tumors & $\begin{array}{l}\text { Osteosarcoma* } \\
\text { Chondrosarcoma* } \\
\text { Rhabdomyosarcoma } \\
\text { Primitive neuroectodermal tumor } \\
\text { (PNET) } \\
\text { Malignant peripheral nerve sheath } \\
\text { tumors } \\
\text { Synovial sarcoma } \\
\text { Lymphoma } \\
\text { Plasmacytoma } \\
\text { Metastasis }\end{array}$ \\
\hline Post-traumatic lesions & $\begin{array}{l}\text { Intramuscular hematoma* } \\
\text { Myositis ossificans } \\
\text { Pseudoaneurysm } \\
\text { Displaced 3rd molar teeth }\end{array}$ \\
\hline Developmental lesions & $\begin{array}{l}\text { Vascular malformations* } \\
\text { Dermoid and epidermoid cysts } \\
\text { Cephalocele and meningocele }\end{array}$ \\
\hline Pseudolesions & $\begin{array}{l}\text { Denervation atrophy* } \\
\text { Masseteric hypertrophy* } \\
\text { Accessory parotid tissue* } \\
\text { Rhabdomyolysis } \\
\text { Lateral pterygoid muscle changes in } \\
\text { TMJ disease }\end{array}$ \\
\hline $\begin{array}{l}\text { Lesions extending into } \\
\text { masticator space }\end{array}$ & $\begin{array}{l}\text { Nasopharyngeal carcinoma* } \\
\text { Oral cavity carcinoma* } \\
\text { Parotid malignancy* } \\
\text { Minor salivary gland tumor* } \\
\text { Odontogenic tumors* } \\
\text { Maxillary sinus malignancy } \\
\text { Juvenile angiofibroma* } \\
\text { Pigmented villonodular synovitis } \\
\text { Synovial chrondromatosis } \\
\text { Extracranial meningioma }\end{array}$ \\
\hline Post-treatment change & $\begin{array}{l}\text { Recurrence versus post-radiation* } \\
\text { Osteoradionecrosis* } \\
\text { Radiation-induced sarcoma } \\
\text { Bisphosphonate-related osteonecrosis } \\
\text { of the jaw* }\end{array}$ \\
\hline
\end{tabular}

Asterisk (*) denotes the most commonly reported lesions in the masticator space
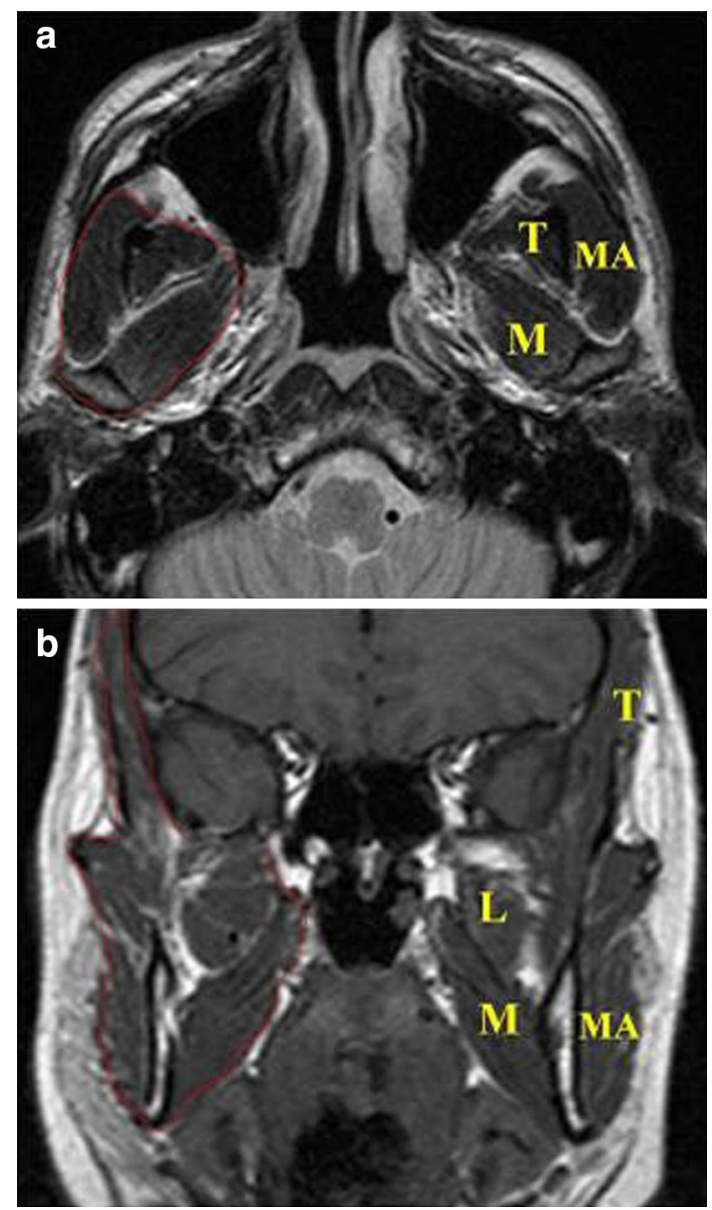

Fig. 1 Normal masticator space at MR imaging: a axial T2-weighted image shows the normal masticator space. Note the intermediate signal intensity of the muscles of mastication. b Coronal T1-weighted image shows the normal masticator muscles. The red line delineates the masticator space. $L$ lateral pterygoid muscle, $M$ medial pterygoid muscle, $M A$ masseter muscle, $T$ temporalis muscle

masticator space. The infratemporal fossa is the cranial extension of the masticator space adjacent to the skull base being the portion between the pterygopalatine fossa medially and the zygomatic arch laterally. The submasseteric space is a potential space located between the masseter muscle and the ramus of the mandible. There is no fascial division between these subspaces, and pathological processes can spread continuously from one to the other [1-5].

\section{Methods of examination}

Magnetic resonance (MR) imaging

The standard MR imaging examination of the masticator space should include the application of a T2-and 
T1-weighted fast spin-echo (SE) sequence, an axial short inversion time inversion-recovery (STIR) sequence, and fat-saturated T1-weighted imaging with a gadoliniumbased contrast material. The image planes are mainly axial or coronal and may be sagittal. Section thickness should be 3-4 mm [1-4]. Diffusion MR imaging has been used to differentiate malignant tumors of the masticator space from benign lesions [7] and infection [8], as well as for differentiation of recurrent tumors from post-treatment changes [9]. MR spectroscopy has a role in differentiation of chronic infection from malignancy, but of limited value [10]. Dynamic contrast-enhanced MR imaging and dynamic susceptibility-weighted contrast-enhanced MR imaging also show promise for characterizing space soft tissue tumors of the masticator space $[3,11]$.

Computed tomography (CT)

Multidetector CT of the masticator space is performed in the axial plane beginning from the skull base down to the base of the neck after intravenous administration of contrast material. Coronal and sagittal images may be reconstructed from the axial sections [3, 5]. PET/CT using fluoro-deoxy-glucose as a tracer (FDG-PET) is sensitive for detection of distant metastatic foci and to differentiate recurrent tumors from post-radiation changes [12]. Recently, CT perfusion [13] and dual energy CT [14] have been used for characterization of head and neck masses including masticator space lesions.

MR imaging is the first-line study for the evaluation of suspected masticator space mass lesions, especially with a strong suspicion that the lesion is neoplastic. CT is the method of choice in patients suspected to suffer from inflammatory disease or in patients with contraindications for MR imaging [1-3].

\section{Interpretation}

Differentiating malignancy from inflammatory lesions

Routine contrast $\mathrm{CT}$ and MR imaging are commonly used for differentiation of malignancy from inflammatory lesions in the masticator space. Abscesses usually appear as well defined marginally enhanced lesions; on the other hand, malignancy shows an inhomogenous pattern of contrast enhancement with ill-defined margins [1-5]. However in some cases, this differentiation is difficult with routine CT and MR imaging. Diffusion MR imaging and MR spectroscopy helps in this differentiation. Malignancy reveals restricted diffusion with low ADC value compared to inflammatory lesions at diffusion [7-9]. There is a significant difference in the choline signals and choline/ creatine between malignant tumors and inflammatory lesions of the masticator space [10].

Differentiating malignancy from benign lesions

Although differentiating benign lesions from malignant tumors is often difficult by routine imaging alone, certain characteristic imaging features such as calcification and MR signal intensity can be helpful in narrowing the list of differential diagnoses [1-4]. Advanced MR imaging such as diffusion MR imaging [7] and dynamic susceptibility-contrast MR imaging [11] may aid in this differentiation. Benign tumors show higher ADC value compared to malignant tumors; however, some overlap has been reported. Malignant tumors tend to show earlier and faster uptake of contrast material than benign tumors at dynamic contrast study [1-5].

Differentiating primary tumors from tumors extending into the masticator space

The epicenter of tumors originating from the masticator space located within the masticator muscles or the mandible and located anterior to the fatty parapharyngeal space. The epicenter of small tumors can be identified; however, the origin of the large aggressive tumors may be difficult to determine with imaging [1-4].

\section{Inflammatory lesions}

\section{Role of imaging}

In inflammatory lesions of the masticator space, it is crucial to determine the source of infection, extent of the lesion, to describe abscesses, and to detect potential osteomyelitis of the mandible and skull base in order to plan appropriate treatment. CT is the modality of choice, as it demonstrates the source of infection and may be helpful in depicting cortical erosion in osteomyelitis. However, MR imaging more accurately delineates inflammation involving the soft tissues [1-4].

Origin of inflammatory lesions

Inflammatory lesions of the masticator space commonly arise from odontogenic infections ( $80 \%$ ), although other sources such as malignant otitis externa, maxillary sinus fracture, and parotid infection are possible etiologies as well $[3,15]$.

Phlegmon versus abscess

An abscess is defined as a drainable cavity of infected debris, whereas a phlegmon is an infected tissue with no necrosis. A fluid collection with peripheral rim 

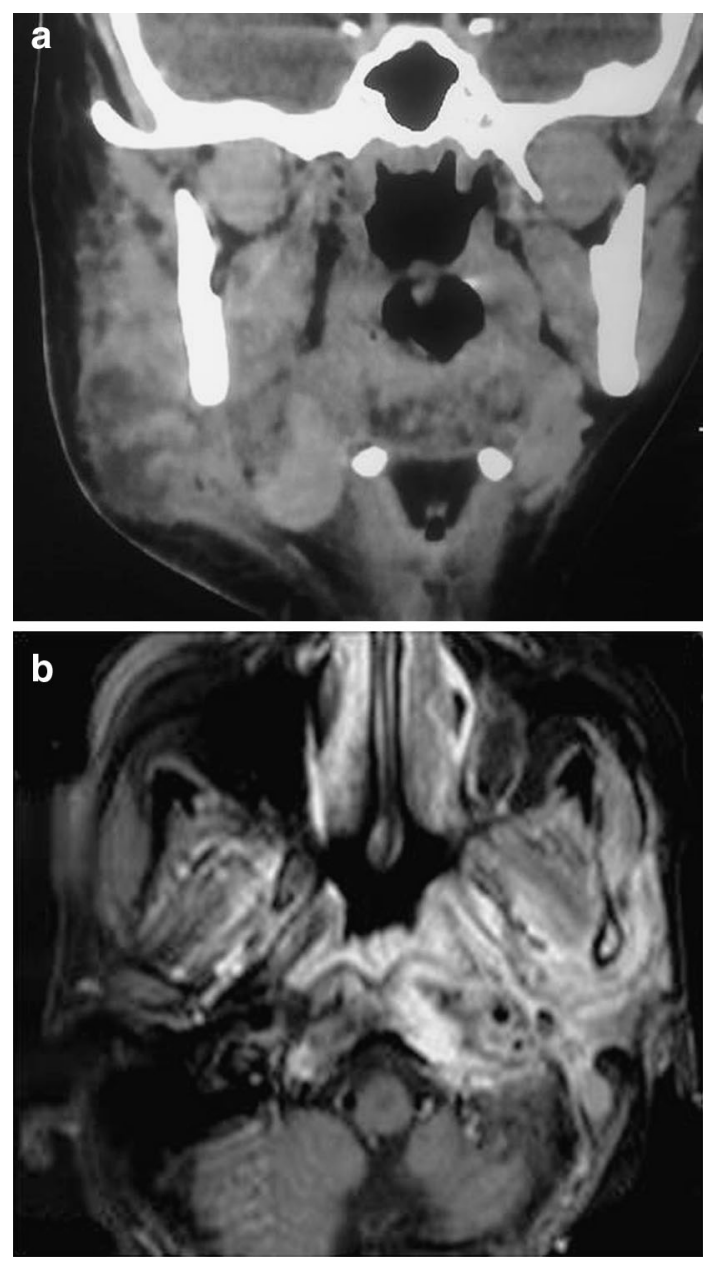

Fig. 2 Masticator space infection: a coronal CT scan shows diffusely enlarged muscles of the right masticator space with linear strands in the overlying subcutaneous soft tissue. b Axial contrast T1-weighted image in another patient shows intense contrast enhancement is seen in the left masticator space. The lesion extends into the left parapharyngeal space and the prevertebral fascia as well as the soft tissue of the nasopharynx enhancement on CT has been considered as the classic imaging finding for an abscess, whereas phlegmons have been described as low-density edematous tissue without discrete peripheral enhancement. At MR imaging, a phlegmon appears as diffuse enlarged muscles of mastication and exhibits high signal intensity on T2-weighted images, low to intermediate signal on T1-weighted images, and diffuse contrast enhancement [1-4] (Figs. 2, 3).

\section{Localization}

Of the masticator muscles involved in inflammatory lesions, the masseter (76\%) and medial pterygoid (63\%) muscles are most often affected. The temporalis $(26 \%)$ and lateral pterygoid ( $21 \%)$ muscles were less frequently involved [16].

\section{Extension of inflammatory lesions}

Masticator space infection may extend into the parapharyngeal space, prevertebral space, temporal fossa (Fig. 3), and the orbit. Infection in the masticator space might easily spread to the base of the skull [1-4].

\section{Osteomyelitis}

Masticator space infection may be associated with osteomyelitis of the mandible. At MR imaging, acute osteomyelitis may be demonstrated as loss of the normal signal void of cortical bone with obliteration of the normal high signal from medullary fat on T1-weighted images. T2weighted or STIR images may demonstrate subperiosteal fluid or increased signal intensity within the medullary cavity of the mandible. In chronic osteomyelitis, computed tomography demonstrates medullary sclerosis, periosteal

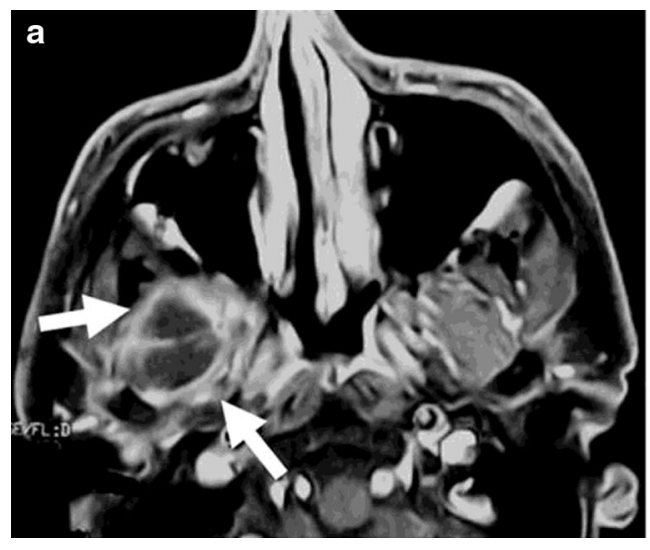

Fig. 3 Masticator space abscess: a axial contrast T1-weighted image scan at lower level shows a multiloculated marginally enhanced abscess (long arrows) in the right masticator space. b Coronal

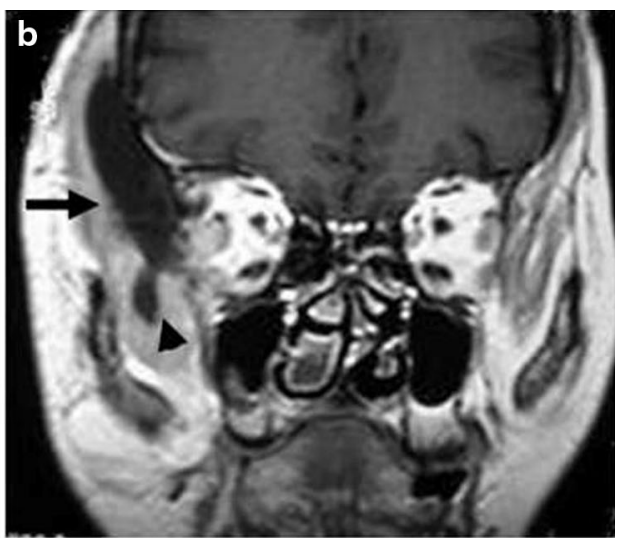

contrast T1-weighted image shows extension of the abscess (arrowhead) into the suprazygomatic part of the right masticator space (long arrow) 


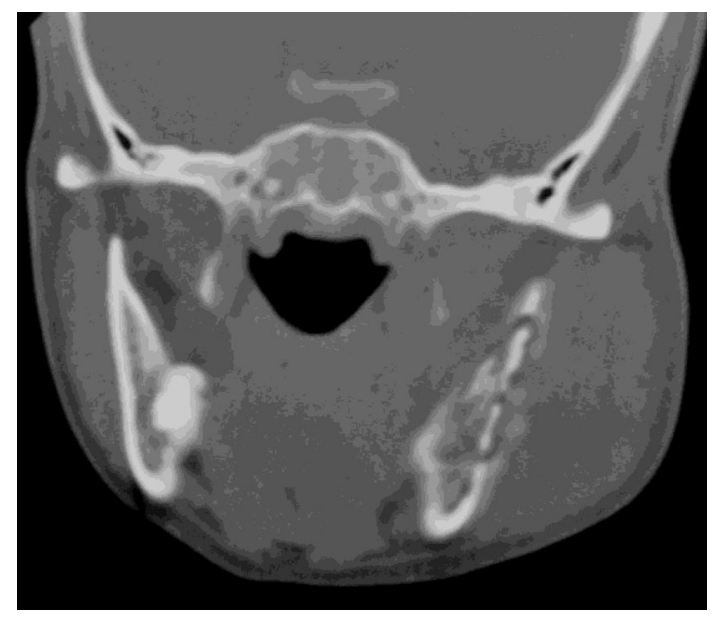

Fig. 4 Osteomyelitis of the mandible: coronal CT scan shows medullary sclerosis, periosteal reaction, and sequestration formation of the mandible that are associated with an enlarged masseter muscle

reaction and sequestration formation of the mandible [17] (Fig. 4).

\section{Atypical (mycobacterial and fungal) infection}

Fungal pathogens such as aspergillus and mucormycosis can gain access directly from an infected paranasal sinus [3]. Tuberculous disease is usually due to hematogenous spread [18]. The CT and MR imaging of these atypical infections are nonspecific and indistinguishable from those of other causes of masticator space infection [1-4]. Actinomycosis is an important infection that causes mass formation and is difficult to distinguish from malignant tumors [19].

\section{Parasitic infection}

Rarely, parasitic diseases have been reported in the masticator space. Hydatid cysts appear as well defined simple cysts with high signal intensity on T2-weighted images. Also, cysticercosis has been reported in the masseter muscle as having high signal intensity on T2-weighted images with marginal enhancement $[20,21]$.

\section{Granulomatous lesions}

Granulomatosis with polyangiitis (Wegener's granulomatosis) is a rare necrotizing vasculitis disorder characterized by a triad of necrotizing granuloma in the upper and lower respiratory tract, necrotizing vasculitis and glomerulonephritis. Granulomatosis with polyangiitis may spread to the masticator space directly or perineurally along the mandibular nerve. On MR imaging, the granulomatous lesions show hypointense signal on both T2-weighted and T1-weighted sequences. Contrast enhancement is usually observed [19].

\section{Benign tumors}

Nerve sheath tumors (schwannoma and neurofibroma)

Nerve sheath tumors are the most frequent benign tumors of the masticator space. Of these, the schwannoma is the most common tumor, followed by neurofibroma. These tumors are related to the mandibular division of the trigeminal nerve [1-4]. Schwannoma appears as well circumscribed fusiform mass within the masticator space with extension along this nerve through the foramen ovale (Fig. 5). On CT, schwannoma is most commonly higher in attenuation than adjacent muscle and show avid contrast enhancement. MR imaging demonstrates intermediate signal on T1-weighted images and hyperintensity on T2-weighted images with marked contrast enhancement. A large tumor shows a heterogeneous appearance [22-24]. On the other hand, MR imaging of neurofibroma is characterized by heterogeneity on T2weighted images, with heterogeneous contrast enhancement. Occasionally, neurofibroma may occasionally exhibit a target pattern of increased peripheral signal intensity and decreased central signal intensity on T2-weighted MR images if there is a central fibrous core [4, 23]. The plexiform neurofibromas most commonly involve branches of the trigeminal nerve. Plexiform neurofibromas pass along the nerves in a longitudinal manner and extend along several branches. The incidence of plexiform neurofibromas in patients with neurofibromatosis type 1 is $25-50 \%$. On CT scan, the tumors tend to show low attenuation and do not enhance. On MR imaging, the masses are of low signal intensity on T1-weighted images and are hyperintense on T2 images with variable enhancement [1-5].

\section{Hemangioma}

Hemangioma is commonly seen in children and tends to afflict females. It presents shortly after birth, grows rapidly, peaks at 1-2 years, and then usually shows slow spontaneous regression. Hemangiomas tend to have a low signal on T1-weighted images and a bright signal on T2weighted images. Flow voids of blood vessels within the mass and intense contrast enhancement are fairly characteristic [25].

\section{Fibrosing inflammatory pseudotumor}

Fibrosing inflammatory pseudotumor is a nonspecific inflammatory process of uncertain cause that has been most frequently reported in the orbit and rarely involves the masticator space. MR findings of pseudotumors are illdefined margins with hypointensity on T2-weighted images, relatively weak enhancement, and good response to steroid therapy [3, 22]. 


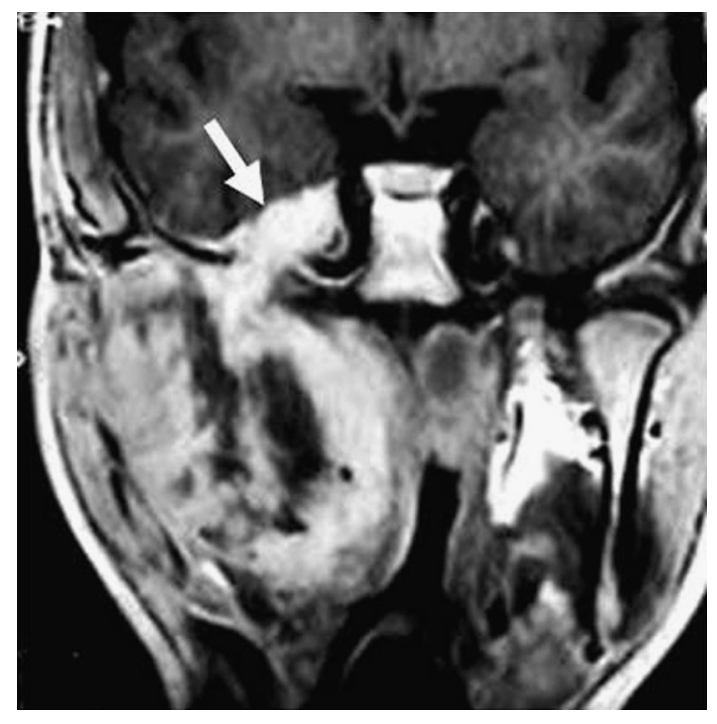

Fig. 5 Schwannoma: post-contrast coronal T1-weighted image shows large enhancing tumor occupying the right masticator space with central non-enhancing regions. Note the tumor extends intracranially (white arrow) via the mandibular nerve through the foramen ovale

Desmoid-type fibromatosis

Aggressive or desmoid-type fibromatosis is a locally aggressive, fibroblastic lesion. It most commonly appears in the second and third decades. The lesion is typically poorly circumscribed, with infiltration of the surrounding soft tissues. The MR imaging appearance of desmoid tumors is variable. The mass is iso- to hypointense to muscle on T1-weighted images and of low, intermediate, or increased signal intensity on T2-weighted images, dependent in part on the cellularity and the amount of collagen that is present. Linear and curvilinear strands of decreased signal on T1-weighted and T2-weighted sequences may represent collagen, and if extensive, should suggest the diagnosis. Intense enhancement is a common feature of these tumors [23, 26] (Fig. 6).

\section{Malignant tumors}

Osteosarcoma

Osteosarcomas of the masticator space may arise from the mandible or from extraskeletal soft tissue of the masticator space. Osteosarcomas of the mandible affect patients in the third decade and one or two decades later than other lesions. On CT, the majority of osteosarcomas have matrix mineralization and calcifications of the osteoid or osteoidlike substance within the tumor, and some tumors show a sunburst effect caused by radiating mineralized tumor
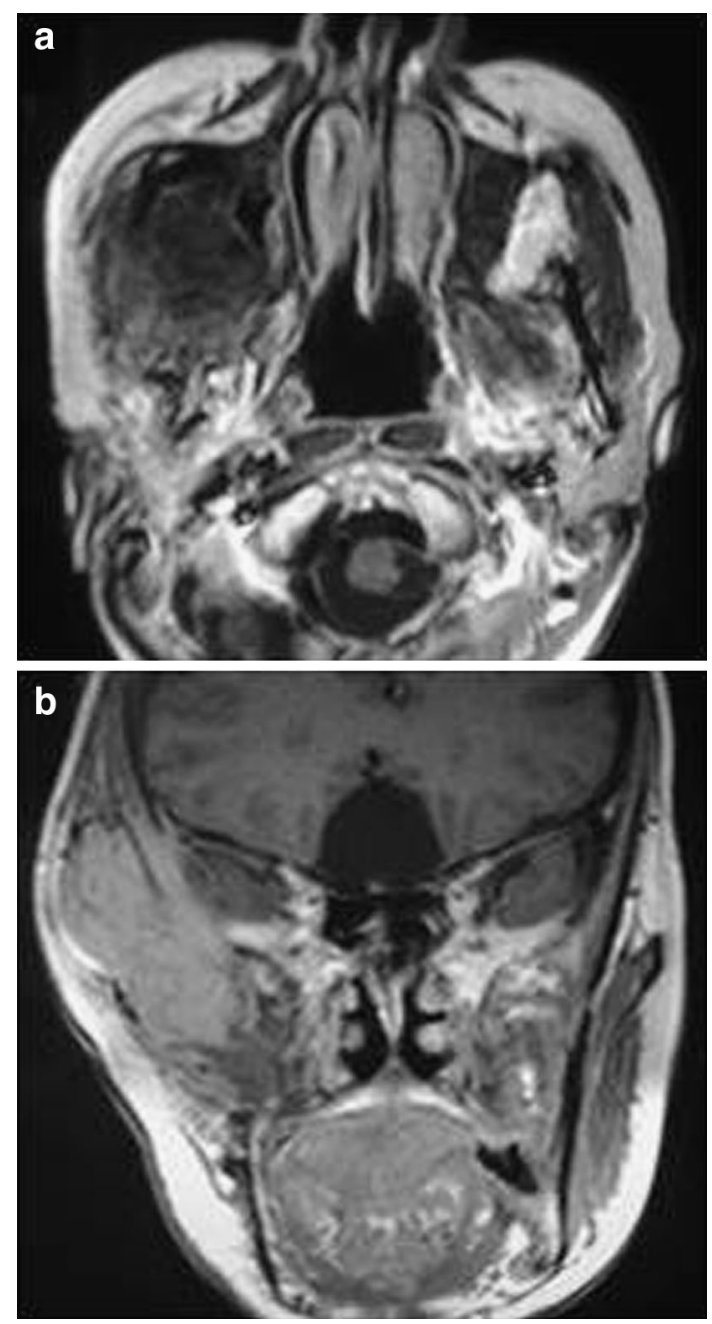

Fig. 6 Fibromatosis: a Axial T2-weighted image shows hypointensity of the right masticator space. b Coronal contrast T1-weighted image shows intense contrast enhancement of the mass, with extension into the suprazygomatic part of the right masticator space

spiculae. On MR imaging, osteosarcoma is of low-tointermediate signal intensity on T1-weighted images and is of high signal intensity on T2-weighted images. Calcifications and new bone formations appear as signal void regions within the lesion [1,27].

\section{Chondrosarcoma}

Chondrosarcomas are malignant cartilaginous tumors that typically manifest in the fourth and fifth decades of life. On CT scan, chondrosarcoma shows a soft tissue mass with characteristic multiple stippled and amorphous areas of calcifications that may be associated with mandibular bone destruction and an inhomogeneous pattern of contrast enhancement. The signal intensity of the chondroid matrix is lower than bone matrix on T1-weighted images. There are hyperintense areas (chondroid tissue) and hypointense 

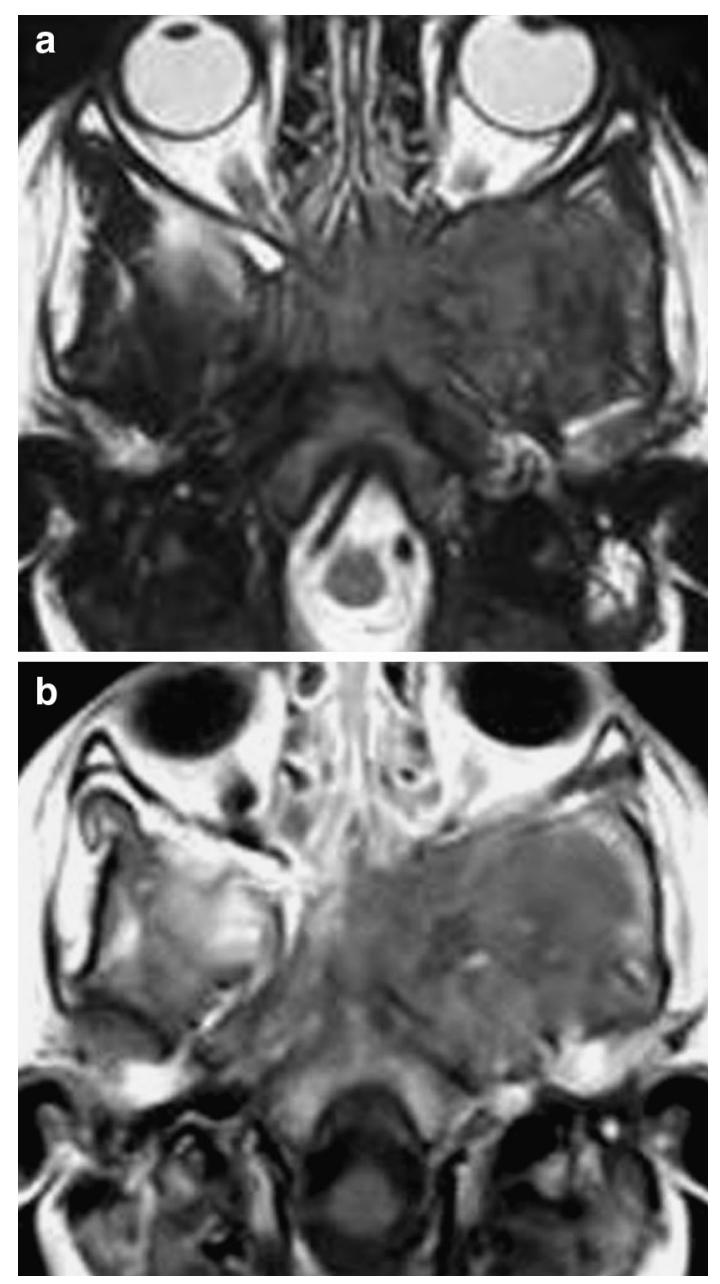

Fig. 7 Rhabdomyosarcoma: a axial T2-weighted image shows an infiltrative mass in the central part of the skull base that extends into the left masticator space. b Axial contrast T1-weighted image shows inhomogeneous pattern of contrast enhancement of the lesion

areas (calcified regions) on T2-weighted images. The tumor may show characteristic curvilinear septal and peripheral enhancement of fibrovascular tissue and nonossified cartilage, a pattern that has been described as "ring-and-arc" [3, 27].

\section{Rhabdomyosarcoma}

Rhabdomyosarcoma, which arises from primitive undifferentiated mesenchymal cells, is the most common soft tissue sarcoma in children but also affects adults. At imaging, rhabdomyosarcomas appear as relatively well circumscribed soft tissue tumors that are often accompanied by lytic bone destruction. On contrast-enhanced CT or MR images, variable tumor enhancement is observed. The signal intensity of tumors on T2-weighted MR images is also variable; occasionally, highly cellular rhabdomyosarcomas may appear iso- to hypointense relative to the brain.
The tumors are usually heterogeneous, may be hemorrhagic or necrotic, and have relatively well circumscribed borders [28] (Fig. 7).

Primitive neuroectodermal tumor (PNET) and extraskeletal Ewing sarcoma

Primitive neuroectodermal tumor (PNET) and extraskeletal Ewing sarcoma are similar malignant soft tissue sarcomas which are likely neuroectodermal in origin. Males are affected more commonly than females. These disorders predominantly affect young adolescents. They have a nonspecific appearance and show low-to-intermediate attenuation on CT without evidence of calcification. MR imaging reveals nonspecific features with low-to-intermediate signal intensity on T1-weighted imaging and high signal intensity on T2-weighted imaging. Tumor margins may be relatively well-defined with a pseudocapsule, or appear infiltrative. MR imaging frequently shows definable high flow vascular channels within the mass, often more peripherally [1-4].

Malignant peripheral nerve sheath tumors (MPNST)

Malignant peripheral nerve sheath tumor is a high-grade sarcoma that may arise from mandibular division of the trigeminal nerve in the masticator space. CT or MR imaging demonstrates a tubular mass along the course of the mandibular division of the trigeminal nerve (V3). These tumors may extend up to the foramen ovale and sometimes spread through it to the Gasserian ganglion in Meckel's cave. It may be difficult to distinguish malignant from benign growths. Large tumor size $(\geq 5 \mathrm{~cm})$, ill-defined infiltrative margins, rapid growth, tumor signal intensity, heterogeneity, and erosion of the skull base foramina out of proportion to tumor size suggest an underlying malignant nature [29] (Fig. 8).

\section{Synovial sarcoma}

Synovial sarcomas are aggressive sarcomas that may arise from soft tissue. CT imaging shows a well demarcated homogeneous mass with a smooth margin. MR imaging characteristics are a mass with iso- or hypointensity on T2-weighted images, isointensity on T1-weighted images, and heterogeneous contrast enhancement. Variable intensity on T2-weighted images is probably due to varying degrees of calcification and cystic or hemorrhagic components [3-5] (Fig. 9).

\section{Lymphoma}

Lymphoma is rarely reported in the masticator space. MR imaging of lymphoma involving the pterygoid muscle demonstrates signal intensity similar to other soft tissue 

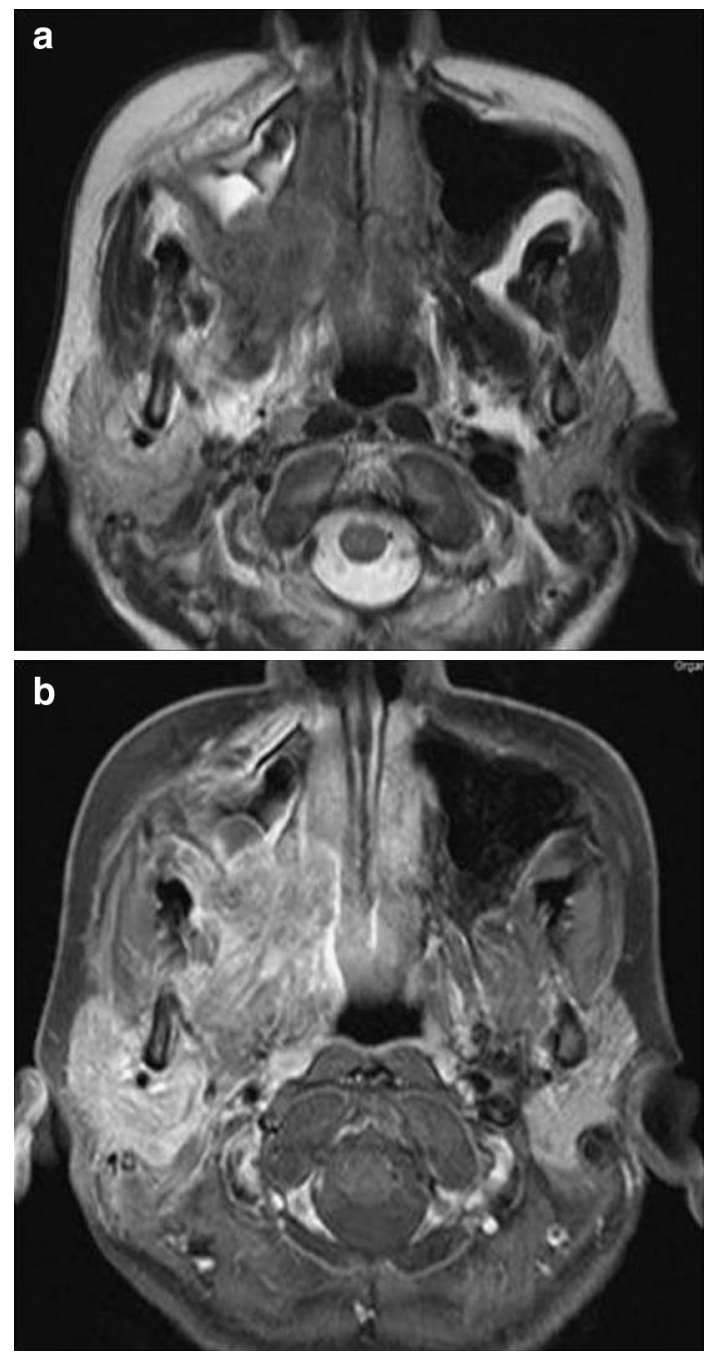

Fig. 8 Malignant peripheral nerve sheath tumor: a axial T2-weighted image shows a hypointense lesion in the right masticator space. Note that the lesion is abutting the posterior wall of the right maxillary sinus. b Axial contrast T1-weighted image shows avid contrast enhancement of the lesion

tumors. Infiltrative lesions of lymphoma show a homogeneous low signal on T1 and high signal on T2-weighted images with intense enhancement. The associated nodal disease, extranodal lymphatic disease (Waldeyer's ring), or multiple other extranodal extralymphatic sites (e.g. sinus, nose, orbit) are involved simultaneously, which suggests the diagnosis of lymphoma [30].

\section{Extramedullary plasmacytoma}

Soft-tissue plasmacytomas of the head and neck have a predilection for the nasal cavity or nasopharynx, but have been reported in the masticator space. At CT, they appear as a soft tissue mass. At MR imaging, plasmocytoma has low signal intensity on T1-weighted MR images, high signal
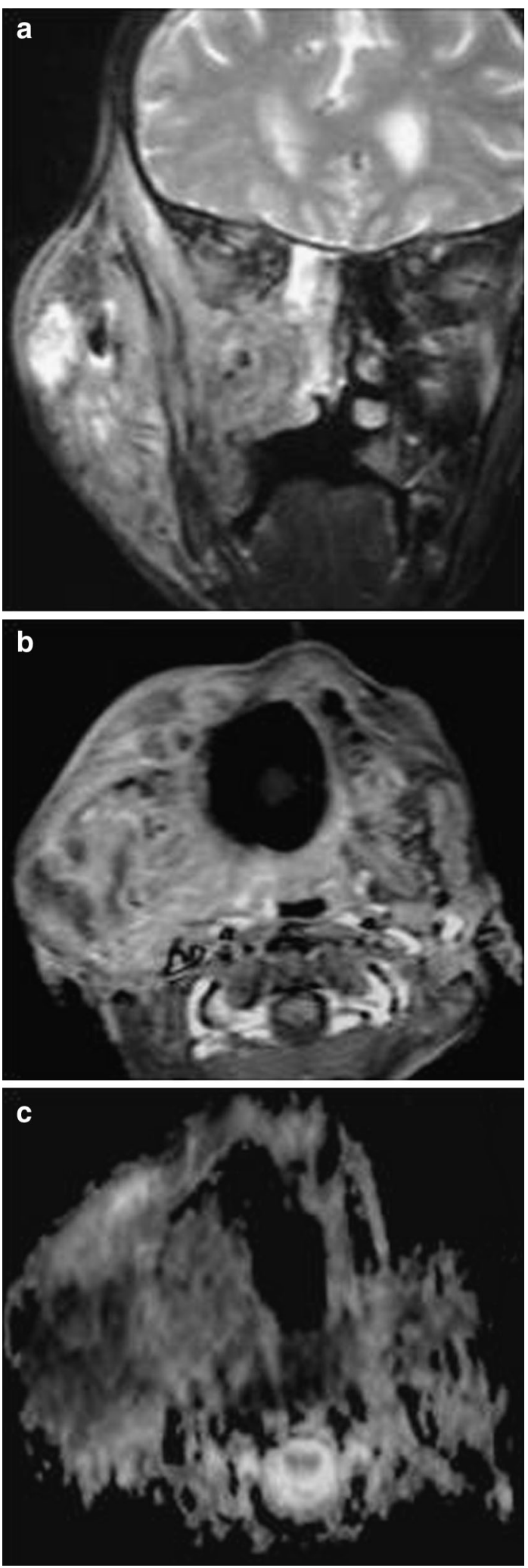

intensity on T2-weighted images, and homogeneous marked enhancement on postcontrast T1-weighted images. Plasmacytomas may show intratumoral flow voids. They exhibit restricted diffusion due to their high cellularity [1-4]. 
4Fig. 9 Synovial sarcoma: a coronal T2-weighted image shows a large heterogeneous soft tissue mass involving the right masticator space. b Axial contrast T1-weighted image shows the lesion's heterogeneous pattern of contrast enhancement with multiple nonenhanced regions and invasion of the right side of the mandible. c ADC map shows restricted diffusion with low ADC value of the tumor

\section{Metastasis}

Metastases to the masticator space are most commonly seen in patients aged 50-70 years. Metastasis is most often located in the mandibular molar region, because of the abundant blood supplies. The CT and MR imaging appearance of metastasis to the masticator space is nonspecific. The lesion may show intense homogeneous, heterogeneous, or marginal contrast enhancement. It may be associated with cortical destruction and invasion of bone marrow of the mandible, with mouth-eaten appearance [1-4].

\section{Post-traumatic lesions}

Condylar fracture and intramuscular hematoma

Fractures of the mandibular condyle may be displaced into the masticator space and can be associated with hematoma of the masticator muscles. Localization of the degree of dislocation of the condylar fracture has significant therapeutic implications. CT scans can be helpful in the assessment of dislocation of fractured bones and associated intramuscular hematoma [31].

\section{Myositis ossificans}

Myositis ossificans is a benign, self-limited, proliferative mesenchymal response to soft tissue injury, resulting in formation of mature bone in the periphery of muscles of mastication by 6-8 weeks following trauma. CT demonstrates a well-defined geometric hypodense mass with peripheral calcification in the earlier phases, when mature, dense calcification can be seen. Familial forms have been reported [22].

\section{Pseudoaneurysm}

Pseudoaneurysm is usually post-traumatic and can be seen within the masticator space when it arises from branches of the internal maxillary artery. CT angiography or MR angiography better delineates the patent and thrombosed part of the aneurysm [32] (Fig. 10).

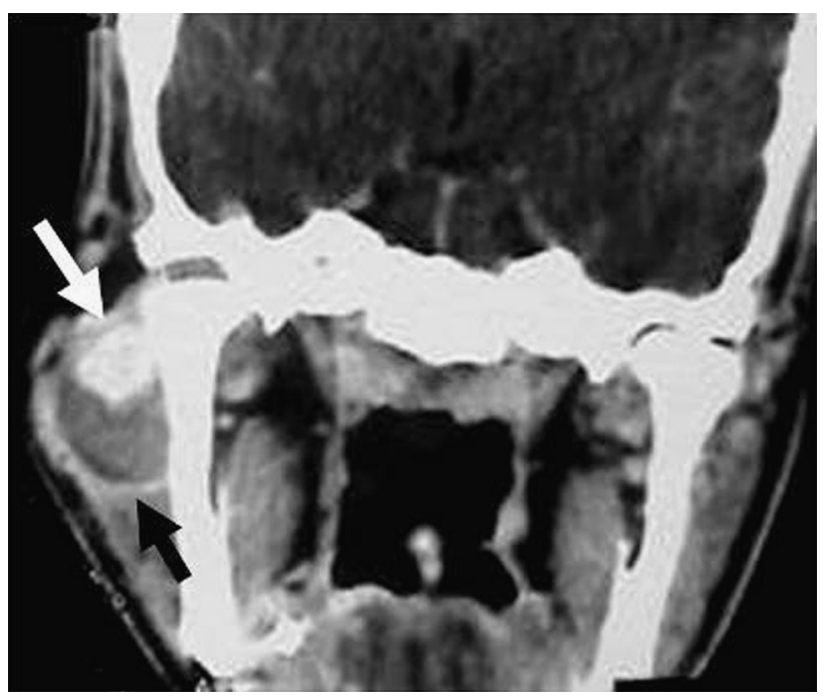

Fig. 10 Post-traumatic pseudoaneurysm: coronal CT scan shows the enhancing patent central part (white arrow) of an aneurysm and the thrombosed non-enhanced peripheral part (black arrow) of pseudoaneurysm

Displaced third molar teeth

Displacement of maxillary third molars into the infratemporal fossa is usually associated with an incorrect extraction technique. These teeth usually displace through the periosteum into the infratemporal fossa just adjacent to the lateral pterygoid plate and inferior to the lateral pterygoid muscle. CT can provide an exact anatomical location [33].

\section{Developmental lesions}

Vascular malformations

Low flow venous malformations are commonly located in the masseter muscle. The lesion is seen as lobulated mass and CT may reveal the characteristic phleboliths, which show signal voids on MR imaging (Fig. 11). The enhancement pattern may be patchy and delayed or homogeneous and intense. Lymphangioma lesions are usually seen in the posterior triangle of the neck and they may spread to the masticator space. It appears as a multicystic lesion that insinuates between structures. High flow arterial malformations are uncommon in the masticator space. On MR imaging, it appears as multiple signal voids which represent dilated tortuous hypertrophied vascular structures [15, 25]. Time resolved imaging of contrast kinetics (TRICKS) MRA better delineates the arterial feeder, venous drainage, and nidus of high flow arterial vascular malformations [34]. 


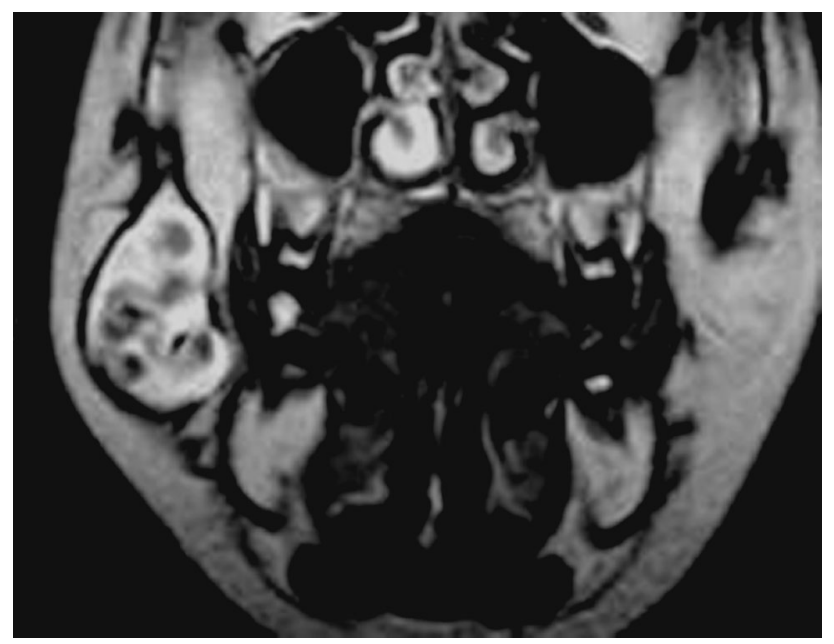

Fig. 11 Low-flow venous malformation: axial T2-weighted image shows hyperintense mass involving the right masseter muscle. Signalvoid regions of phleboliths are seen within the lesion

\section{Dermoid and epidermoid}

Dermoid and epidermoid cysts rarely originate from the masticator space, usually its suprazygomatic compartment. [2] On CT, dermoid cysts typically appear as low-density, well-circumscribed, unilocular masses that may or may not contain fat. In the absence of fat, epidermoid and dermoid cysts are indistinguishable. Epidermoid cysts usually contain desquamated keratin. On MR, epidermoid cysts are of low signal intensity on T1-weighted images (Fig. 12) and high signal intensity on $\mathrm{T} 2$-weighted images. One characteristic MR finding of the epidermoid is a high signal on diffusionweighted images. Dermoid lesions present a more variable appearance, depending upon their fat content, varying from hyper to hypointense on T2-weighted images [35].

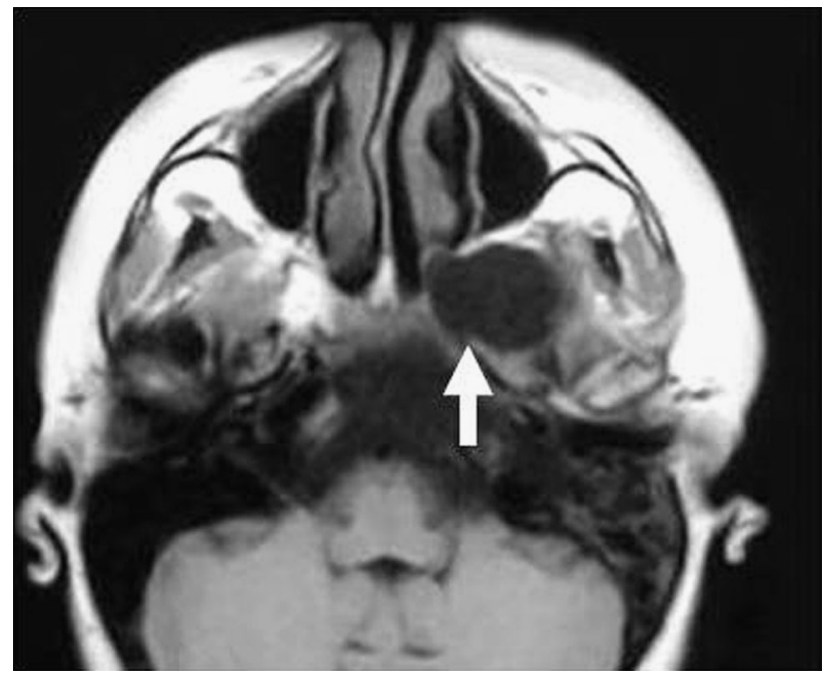

Fig. 12 Dermoid cyst: axial T1-weighted image shows a well defined cystic lesion (arrow) is seen in the left masticator space
Meningocele and cephalocele

Meningoceles and cephaloceles are rare lesions representing protrusions of arachnoid or dura mater through skull defects into the masticator space. They may be considered as congenital, spontaneous, or secondary. At imaging, cephaloceles are smoothly marginated and have the same signal intensity characteristics as CSF with all MR imaging sequences [36].

\section{Pseudolesions}

Denervation atrophy of masticator muscles

Denervation atrophy of the masticator muscles occurs as a result of perineural tumor infiltration along the mandibular division of the trigeminal nerve. In the acute stage, increased volume, increased signal intensity at T2-weighted images, and increased gadolinium enhancement is present on MR imaging and may mimic a mass lesion on the affected side. In the chronic stage, fatty replacement of the muscle fibers and volume loss become evident on the affected side, and the normal side can be mistaken for a mass lesion by an unaware radiologist [37].

\section{Masseteric hypertrophy}

Masseteric hypertrophy is a relatively rare benign condition characterized by enlargement of the masseter muscles. This is bilateral in approximately half of patients, and most cases exhibit habitual teeth grinding. In unilateral cases with the preservation of soft tissue planes, associated pterygoid and temporalis muscle enlargement is useful to improve diagnostic confidence [1-4].

\section{Accessory Parotid tissue}

Accessory parotid tissue lies superficial to the masseter muscle along Stensen's duct in approximately $20 \%$ of patients. Asymmetry of the accessory parotid tissue may mimic a masseteric mass on palpation. This is easily distinguished on MRI, which reveals tissue identical in signal to the parotid gland [1-3].

\section{Rabdomyolysis of muscles}

Rhabdomyolysis is defined as a disintegration of skeletal muscles that causes myoglobinuria, raised creatine kinase, and renal failure in severe cases. CT scans initially show areas of low attenuation within affected muscles, which may become hyperattenuated in later stages, with or without subsequent atrophy. MR imaging shows hyperintensity on T2-weighted images with avid contrast 
enhancement and may demonstrate $\mathrm{T} 1$ hyperintensity later in the course of the disease in some patients [38].

Lateral pterygoid muscle changes

in temporomandibular joint disease

In temporomandibular joint dysfunction syndrome, increased signal intensity on T2-weighted images can be identified in the superior head of the lateral pterygoid muscle. This change may reflect increased fluid signal intensity related to muscular edema or fatty change, or both, secondary to atrophy [39].

\section{Lesions extending into the masticator space}

The masticator space can be invaded by malignancy, benign tumors, and aggressive infection. These lesions may spread directly or via perineural spread into the masticator space $[4,40]$.

\section{Perineural spread}

The perineural spread into the masticator space is seen in adenoid cystic carcinoma and squamous cell carcinoma, but it may be reported in lymphoma and malignant melanoma and rarely in Granulomatosis with polyangiitis [40, 41]. Perineural spread to the masticator space is along the mandibular division of the trigeminal nerve (V3) and may be along the auriculotemporal nerve. Malignant tumors in any anatomic location supplied by the mandibular nerve can have retrograde perineural spread to the masticator space. MR imaging revealed enlargement or abnormal enhancement of the mandibular nerve (V3), obliteration of the neural fat pads in the foramen oval, or foraminal enlargement. Mandibular nerve involvement is best seen on coronal T1-weighted contrast-enhanced MR imaging with fat saturation [41, 42] (Fig. 13).

\section{Nasopharyngeal carcinoma}

The frequency of masticator space involvement in nasopharyngeal carcinoma is $19.7 \%$. Nasopharyngeal carcinoma demonstrates intermediate to high signal intensity on T2-weighted images, low signal intensity on T1-weighted images, and moderate enhancement on contrast-enhanced images. MR imaging provides excellent visualization of the soft tissue planes of the nasopharynx and is superior to CT for detecting perineural spread of tumor. Lymphadenopathy is present in up to $90 \%$ of patients, with the retropharyngeal chain often being the first involved nodal site [42] (Fig. 13).
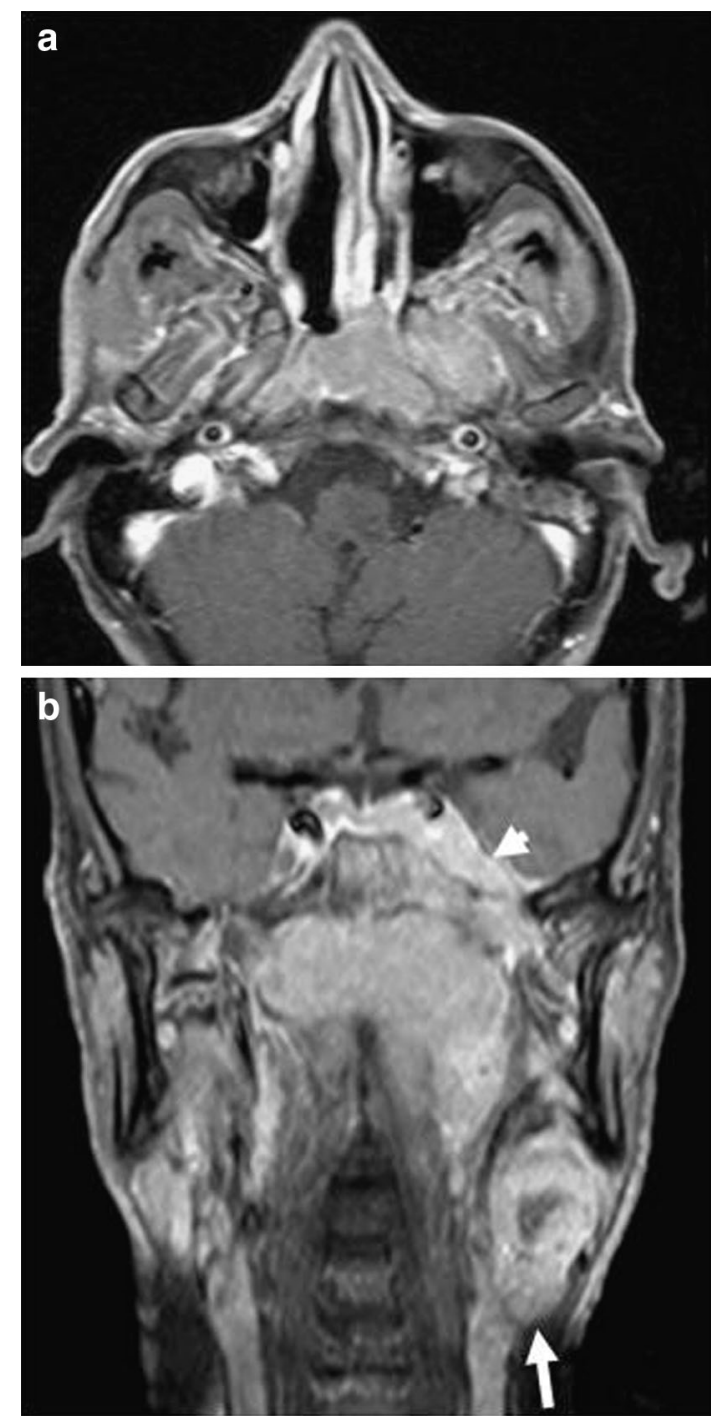

Fig. 13 Nasopharyngeal carcinoma: a Axial contrast T1-weighted image shows intense enhanced nasopharyngeal carcinoma with extension into the left masticator space. b Coronal contrast T1weighted image shows perineural extension of the tumor (arrowhead)-associated enlarged necrotic upper-left deep cervical lymph node (arrow)

Oral cavity carcinoma

Squamous cell carcinomas originating from the retromolar trigone, tonsillar region, gingival and buccal space can also infiltrate the masticator space. The tumor may spread along the anterior portion of the mandibular ramus with bone destruction, or extend directly into the masticator space through the fat space between the medial pterygoid muscle and the ramus with or without bone destruction. Also, these tumors may spread perineurally through the mandibular deviation of the trigeminal menial nerve. The tumor demonstrates intermediate to high signal intensity on T2weighted images, low signal intensity on T1-weighted 
images, and moderate enhancement on contrast-enhanced images [2-4].

\section{Parotid malignancy}

Tumors in the superficial lobe of the parotid gland may spread along the neurovascular bundle into the masticator space via holes in the parotid fascia where the external carotid artery and nerves perforate the fascia and enter the masticator space. Also, a tumor in the superficial portion of the gland depresses the masseter muscle anteriorly. A tumor in the deep portion spreads through the stylomandibular tunnel into the parapharyngeal space and thereafter presses the medial pterygoid muscle [3-6].

Minor salivary gland tumors

Tumors of minor salivary glands in the parapharyngeal space can often displace/infiltrate the masticator space. Of all the benign tumors, pleomorphic adenoma is the commonest. Pleomorphic adenoma can arise from displaced or aberrant salivary gland tissue within a lymph node in the parapharyngeal space. Pleomorphic adenomas usually show the following MR appearance: hyperintense signal intensity on T2-weighted sequences, related to their myxoid component, and often pronounced enhancement. Presence of an intact fat plane helps in distinguishing benign tumors from malignant ones [1-4].

\section{Odontogenic tumors}

Ameloblastoma is the most common odontogenic tumor that may extend into the masticator space. Typical imaging findings are unilocular or multilocular (soap foam or honeycomb) lesions, often accompanied by absorption of the apices of adjacent teeth (40\%). At CT, cystic areas of low attenuation and enhancing solid areas of isoattenuation are seen. MR imaging of ameloblastoma presents several characteristic findings: multilocularity, mixed solid and cystic components, irregularly thickened walls, papillary projections, and marked enhancement of the walls and septa [43].

\section{Sinus malignancy}

Extension of nasal and paranasal sinus malignancy posteriorly by direct extension or perineural spread may result in neoplastic invasion of the masticator space [44].

Juvenile angiofibroma

Juvenile angiofibromas are uncommon tumors that usually occur in adolescent boys. These tumors virtually always arise from the pterygopalatine fossa. However, juvenile angiofibroma can be confined to the pterygoid muscle region, without involvement of the nasopharynx. The mass revealed multiple signal void regions on both T1- and T2weighted images that associated with intense contrast enhancement [45] (Fig. 14).

Pigmented villonodular synovitis

Pigmented villonodular synovitis frequently arises in the temporomandibular joint that may extend into the masticator space. This lesion has a predilection to hemorrhage, resulting in hemosiderin deposition. As a result, the tumor characteristically appears as an aggressive mass that partially encases the mandibular condyle and demonstrates low signal intensity on both T1- and T2-weighted MR images [22].

\section{Synovial chondromatosis}

Synovial chondromatosis of the temporomandibular joint is characterized by the development of cartilaginous bodies in the synovial membrane and joint space. At CT, the lesion appears as a mass of water density with calcified loose bodies and bone erosion. MRI may misdiagnose loose bodies but detects joint swelling and accurately defines the boundaries of the lesion. MRI is particularly useful to intracranial extension and internal derangement [1-4].

\section{Extracranial meningioma}

Extracranial meningiomas are classified into 4 subgroups: direct extension from primary intracranial meningioma,

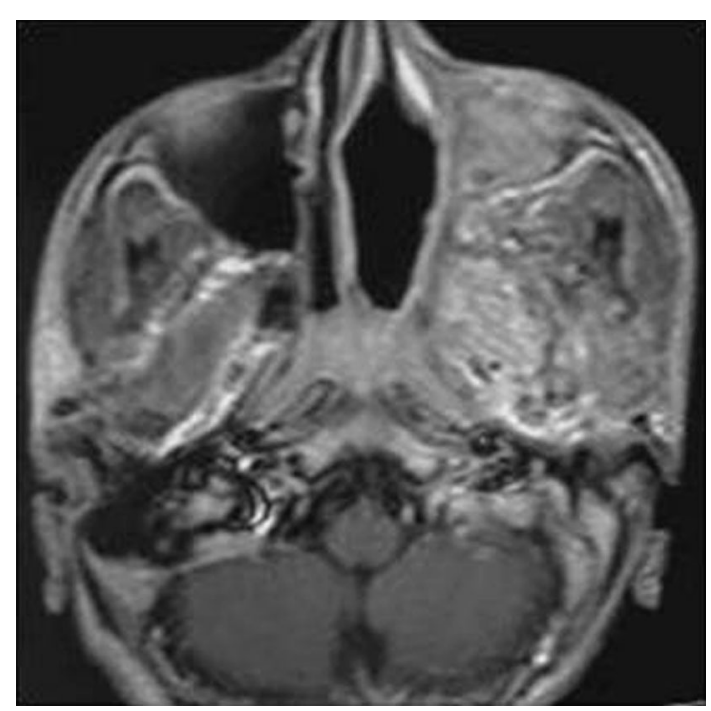

Fig. 14 Juvenile angiofibroma: Axial contrast T1-weighted image shows intense enhanced mass in the left masticator space. The mass shows multiple signal void regions 
extracranial growth from cranial nerve sheath arachnoid cells, extracranial extension from embryonic arachnoid rests without connection to the skull base or cranial nerves, and distant metastasis from intracranial tumors. The typical MR imaging features of meningiomas are isointense or hypointense on T1-WI and isointense or hypointense on T2-weighted images and exhibit marked homogeneous contrast enhancement. On T2-weighted images, fibroblastic and transitional meningiomas are isointense to hypointense, but angiomatous and meningothelial meningiomas are usually hyperintense [46].

\section{Post-treatment}

Response to therapy and tumor recurrence

Differentiating fibrosis from tumor recurrence is difficult on routine CT. MRI can differentiate mature scar tissue, which shows low T2 signal and no contrast enhancement, from tumor, which has an intermediate $\mathrm{T} 2$ signal with moderate contrast enhancement $[47,48]$. At CT perfusion, recurrent disease can be differentiated on the basis of significantly higher blood flow and blood volume from posttherapeutic changes [49]. At PET/CT, recurrent tumors show uptake of radionuclide tracer, but fibrosis does not [48]. Also, recurrence shows restricted diffusion compared to unrestricted diffusion of post treatment changes [50]. Percentage changes in Cho levels at MR spectroscopy after chemo-radiotherapy may serve as a marker of residual cancer in a post-treatment mass [51]. Trismus is most commonly due to abnormality of masticator muscles as a result of the effects of radiation and rarely is secondary to damage of the mandibular nerve. Also, trismus may be due to osteoradionecrosis of the mandibular ramus and temporomandibular joint. Irradiation of the muscles of mastication may produce fibrosis. There is diffusely increased signal intensity of the masticator muscles on T2-weighted images with variable degree of enhancement [52] (Fig. 15).

\section{Osteoradionecrosis of the mandible}

Osteoradionecrosis of the mandible may occur after irradiation. Imaging findings include areas of osteolysis and mixed sclerosis within the irradiation portal. Fragmentation and sloughing of necrotic bone may also be found. The adjacent masticator muscles show abnormal hyper intensity on T2-weighted images, intense diffuse enhancement, and mass-like thickening that may mimic tumor recurrence or osteomyelitis. CT in these patients reveals cortical disruption, trabecular disorganization, fragmentation, and possible pathological fractures [53].

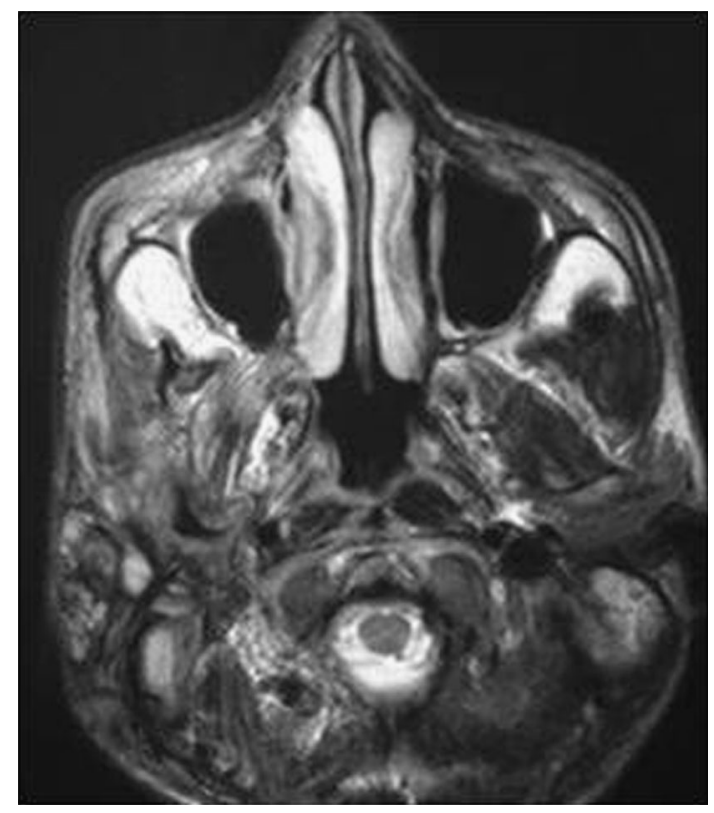

Fig. 15 Trismus with post radiation fibrosis: Axial T2-weighted image shows diffuse increased signal intensity with decreased volume of the of the right masticator muscles

\section{Radiation-induced sarcoma}

Radiation-induced sarcomas arise 5-10 years in the highdose field zone after irradiation. Radiation-induced sarcomas have varied histologies, including osteosarcoma, malignant fibrous histiocytoma, chondrosarcoma, and malignant nerve sheath tumors. The presence of a heterogeneous tumor, or rapidly growing large destructive mass that displays different signal intensity from the primary tumor, within the radiation field that occurs after a sufficient latency period should suggest the possibility of a radiation-induced sarcoma. The presence of calcification or ossification points strongly to a diagnosis of radiationinduced sarcoma [42, 54].

Bisphosphonate-related osteonecrosis of the jaw

Bisphosphonate-related osteonecrosis of the jaw is characterized by nonhealing exposed bones of the jaw in patients who have undergone bisphosphonate treatment for bone metastasis and osteoporosis. CT scan shows osteolysis, sclerotic lesions, periosteal reaction, narrowing of the marrow space, and fractures. The lesion typically shows decreased signal intensity on T1-weighted images. T2weighted images revealed intermediate or slightly increased signal intensity in early disease and increased or decreased signal intensity in later stages of disease. Contrast material-enhanced variable [55]. 


\section{Conclusion}

In conclusion, imaging plays an essential role in the assessment of the masticator space. Consideration of the various inflammatory, neoplastic or vascular lesions, lesions extending into the space, and recognition of pseudomasses allows an appropriate radiological differential diagnosis to be formulated. Accurate delineation of the extent of pathology in the masticator space is pivotal for directing drainage procedures for infective lesions, surgical intervention, or radiotherapy planning for neoplastic lesions.

Conflict of interest The author declares that he has no conflict of interest.

\section{References}

1. Faye N, Lafitte F, Williams M, Guermazi A, Sahli-Armor M, Chiras J, et al. The masticator space: from anatomy to pathology. J Neuroradiol. 2009;18:121-30.

2. Connor S, Davitt S. Masticator space masses and pseudomasses. Clin Radiol. 2004;59:237-45.

3. Fernandes T, Lobo JC, Castro R, Oliveira MI, Som PM. Anatomy and pathology of the masticator space. Insights Imaging. 2013;4:605-16.

4. Meltzer DE, Shatzkes DR. Masticator space: imaging anatomy for diagnosis. Otolaryngol Clin North Am. 2012;45:1233-51.

5. Chong VF, Fan YV. Pictorial review: radiology of the masticator space. Clin Radiol. 1996;51:457-65.

6. Galli F, Flor N, Villa C, Franceschelli G, Pompili G, Felisati G, et al. The masticator space. Value of computed tomography and magnetic resonance imaging in localisation and characterisation of lesions. Acta Otorhinolaryngol Ital. 2010;30:94-9.

7. Wang P, Yang J, Yu Q, Ai S, Zhu W. Evaluation of solid lesions affecting masticator space with diffusion-weighted MR imaging. Oral Surg Oral Med Oral Pathol Oral Radiol Endod. 2010;109:900-7.

8. Abdel Razek AA, Nada N. Role of diffusion-weighted MR imaging in differentiation of masticator space malignancy from infection. Dentomaxillofac Radiol. 2013;42:20120183.

9. Abdel Razek AA, Kandeel A, Soliman N, El-shenshawy H, Nada N, Denewer A. Role of diffusion-weighted echo-planar MR imaging in differentiation of residual/recurrent head and neck tumors and post-treatment changes. AJNR Am J Neuroradiol. 2007;28:1146-52.

10. Yu Q, Yang J, Wang P. Malignant tumors and chronic infections in the masticator space: preliminary assessment with in vivo single-voxel 1H-MR spectroscopy. AJNR Am J Neuroradiol. 2008;29:716-9.

11. Razek AA, Elsorogy LG, Soliman NY, Nada N. Dynamic susceptibility contrast perfusion MR imaging in distinguishing malignant from benign head and neck tumors: a pilot study. Eur J Radiol. 2011;77:73-9.

12. Escott EJ. Role of positron emission tomography/computed tomography (PET/CT) in head and neck cancer. Radiol Clin North Am. 2013;51:881-93.

13. Tawfik AM, Razek AA, Elsorogy LG, Soliman NY, Kerl JM, Mack MG, Vogl TJ. Perfusion CT of head and neck: effect of arterial input selection. AJR Am J Roentegenol. 2011;196:1374-80.
14. Tawfik AM, Kerl JM, Razek AA, Bauer R, Nour-Eldin N, Vogl $\mathrm{T}$, et al. Image quality and radiation dose of dual-energy CT of the head and neck compared with a standard $120-\mathrm{kVp}$ acquisition. AJNR Am J Neuroradiol. 2011;32:1994-9.

15. Razek AA, Huang BY. Lesions of the petrous apex: classification and findings at $\mathrm{CT}$ and MR imaging. Radiographics. 2012;32:151-73

16. Schuknecht B, Stergiou G, Graetz K. Masticator space abscess derived from odontogenic infection: imaging manifestation and pathways of extension depicted by CT and MR in 30 patients. Eur Radiol. 2008;18:1972-9.

17. An CH, An SY, Choi BR, Huh KH, Heo MS, Yi WJ, et al. Hard and soft tissue changes of osteomyelitis of the jaws on CT images. Oral Surg Oral Med Oral Pathol Oral Radiol. 2012;114:118-26.

18. Mascarenhas S, Tuffin J, Hassan I. Tuberculous submasseteric abscess: case report. $\mathrm{Br} \mathrm{J}$ Oral Maxillofacial Surg. 2009;47:566-8.

19. AbdelRazek AA, Castillo M. Imaging appearance of granulomatous lesions of head and neck. Eur J Radiol. 2010;76:52-60.

20. Abdel Razek AA, Watcharakorn A, Castillo M. Parasitic diseases of the central nervous system. Neuroimag Clin North Am. 2011;21:815-41.

21. Mittal A, Das D, Aiyer N, Nagaraj J, Gupta M. Masseter cysticercosis - a rare case diagnosed in ultrasound. Dentomaxillofac Radiol. 2008;37:113-6.

22. Abdel Razek AA, Huang B. Soft tissue tumors of the head and neck: imaging-based review of the WHO classification. Radiographics. 2011;31:1923-54.

23. Abdel Razek AA, Castillo M. Imaging lesions of the cavernous sinus: a review. AJNR Am J Neuroradiol. 2009;30:444-52.

24. Servadei F, Romano A, Ferri A, Magri A, Sesenna E. Giant trigeminal schwannoma with parapharyngeal extension: report of a case. J Cranio Maxillofac Surg. 2012;40:e15-8.

25. Baer AH, Parmar HA, Dipietro MA, Kasten SJ, Mukherji SK. Hemangiomas and vascular malformations of the head and neck: a simplified approach. Neuroimaging Clin North Am. 2011;21:641-58.

26. Chihara Y, Mochiki M, Sugasawa M, Nibu K. Fibromatosis of the infratemporal fossa extending to the parapharyngeal space accompanied by trismus. Auris Nasus Larynx. 2003;30:319-23.

27. Abdel Razek AA. Imaging appearance of bone tumors of the maxillofacial region. World J Radiol. 2011;3:125-34.

28. Freling N, Merks J, Saeed P, Balm A, Bras J, Pieters B, et al. Imaging findings in craniofacial childhood rhabdomyosarcoma. Pediatr Radiol. 2010;40:1723-38.

29. Gheisari R, Roozbehi A. Malignant peripheral nerve sheath tumor of the infratemporal fossa. J Craniofac Surg. 2010;21:596-8.

30. Abbott MM, Hasserjian RP, Emerick KS. Marginal zone B-cell lymphoma of the infratemporal fossa: a rare case and review. Laryngoscope. 2010;120:2430-3.

31. Görgü M, Aslan G, Tuncel A, Erdoğan A. Massive expanding hematoma: a late complication of a mandibular fracture. J Oral Maxillofac Surg. 2000;58:1300-2.

32. Pinjala R, Joshi S, Rammurti S. Traumatic pseudoaneurysm of the internal maxillary artery. EJVES Extra. 2007;14:54-5.

33. Selvi F, Cakarer S, Keskin C, Ozyuvaci H. Delayed removal of a maxillary third molar accidentally displaced into the infratemporal fossa. J Craniofac Surg. 2011;22:1391-3.

34. Razek AA, Gaballa G, Megahed A, Elmogy S. Time resolved imaging of contrast kinetics (TRICKS) MR angiography of arteriovenous malformations of head and neck. Eur J Radiol. 2013;82:1885-91.

35. Uppal H, D'Souza AR, De R, Irving R. Dermoid cyst of the infratemporal fossa. J Laryngol Otol. 2002;116:150-2.

36. Connor S. Imaging of skull-base cephalocoeles and cerebrospinal fluid leaks. Clin Radiol. 2010;65:832-41. 
37. Borges A. Imaging of denervation in the head and neck. Eur $\mathbf{J}$ Radiol. 2010;74:378-90.

38. Jain V, Ellingson A, Smoker W. Lateral pterygoid muscle rhabdomyolysis. AJNR Am J Neuroradiol. 2007;28:1876-7.

39. Finden SG, Enochs WS, Rao VM. Pathologic changes of the lateral pterygoid muscle in patients with derangement of the temporomandibular joint disk: objective measures at MR imaging. AJNR Am J Neuroradiol. 2007;28:1537-9.

40. Wei Y, Xiao J, Zou L. Pictorial review: masticator space: CT and MRI of secondary tumor spread. AJR Am J Roentegenol. 2007;189:488-97.

41. Moonis G, Cunnane M, Emerick K, Curtin H. Patterns of perineural tumor spread in head and neck cancer. Magn Reson Imaging Clin North Am. 2012;20:435-46.

42. Abdel Razek AA, King A. MRI and CT of nasopharyngeal carcinoma. AJR Am J Roentegenol. 2012;198:11-8.

43. Auluck A, Shetty S, Desai R, Mupparapu M. Recurrent ameloblastoma of the infratemporal fossa: diagnostic implications and a review of the literature. Dentomaxillofac Radiol. 2007;36:416-9.

44. Loevner L, Sonners A. Imaging of neoplasms of the paranasal sinuses. Neuroimag Clin North Am. 2004;14:625-46.

45. Szymańska A, Szymański M, Skomra D, Szczerbo-Trojanowska M. Extranasopharyngeal angiofibroma of the infratemporal fossa. Otolaryngol Head Neck Surg. 2009;140:433-4.

46. Iaconetta G, Santella A, Friscia M, Abbate V, Califano L. Extracranial primary and secondary meningiomas. Int $\mathrm{J}$ Oral Maxillofac Surg. 2012;41:211-7.
47. Hermans H. Posttreatment imaging in head and neck cancer. Eur J Radiol. 2008;66:501-11.

48. de Bree R, van der Putten L, Brouwer J, Castelijns J, Hoekstra O, Leemans C. Detection of locoregional recurrent head and neck cancer after (chemo)radiotherapy using modern imaging. Oral Oncol. 2009;45:368-93.

49. Razek AAKA, Tawfik A, Elsorogy L, Soliman N. Perfusion CT of head and neck cancer. Eur J Radiol. 2013; doi:10.1016/j.ejrad. 2013.12.008.

50. Abdel Razek AA. Diffusion-weighted magnetic resonance imaging of head and neck. J Comput Assist Tomogr. 2010;34:808-15.

51. Razek AA, Poptani H. MR spectroscopy of head and neck cancer. Eur J Radiol. 2013;82:982-9.

52. Bhatia K, King A, Paunipagar B, Abrigo J, Vlantis A, Leung S, et al. MRI findings in patients with severe trismus following radiotherapy for nasopharyngeal carcinoma. Eur Radiol. 2009;19:2586-93.

53. Hermans R. Imaging of mandibular osteoradionecrosis. Neuroimag Clin North Am. 2003;13:579-604.

54. Bharatha A, Yu E, Symons S, Bartlett E. Pictorial essay: earlyand late-term effects of radiotherapy in head and neck imaging. Canad Assoc Radiol. 2012;63:119-28.

55. Morag Y, Morag-Hezroni M, Jamadar D, Ward B, Jacobson J, Zwetchkenbaum S. Bisphosphonate related osteonecrosis of the jaw: a pictorial review. Radiographics. 2009;29:1971-86. 